\title{
Queen control over reproductive decisions - no sexual deception in the ant Lasius niger
}

\author{
STEPHANIE JEMIELITY and LAURENT KELLER \\ Institute of Zoology and Animal Ecology, University of Lausanne, CH-1015 Lausanne, Switzerland
}

\begin{abstract}
Queen-worker conflicts in social insect societies have received much attention in the past decade. In many species workers modify the colony sex ratio to their own advantage or produce their own male offspring. In some other species, however, queens seem to be able to prevent workers from making selfish reproductive decisions. So far, little effort has been made to find out how queens may keep control over sex ratio and male parentage. In this study we use a Lasius niger population under apparent queen control to show that sexual deception cannot explain queen dominance in this population. The sexual deception hypothesis postulates that queens should prevent workers from discriminating against males by disguising male brood as females. Contrary to the predictions of this hypothesis, we found that workers are able to distinguish male and female larvae early in their development: in early spring workers generally placed only either female or male larvae in the uppermost chambers of the nest, although both types of larvae must have been present. At this time males were only at $11 \%$ of their final dry weight, a developmental stage at which (according to two models) workers would still have benefited from replacing queenproduced males by females or worker-produced males. This study thus demonstrates that sexual deception cannot account for the apparent queen control over colony sex ratio and male parentage in L. niger.
\end{abstract}

Keywords: brood sex discrimination, conflict, Hymenoptera, Lasius, sex allocation, sexual deception

Received 18 November 2002; revision received 4 February 2003; accepted 4 February 2003

\section{Introduction}

Conflicts of interest between individuals play an important role in shaping life in animal societies (Keller \& Reeve 1999). Eusocial Hymenoptera (ants, certain bees and wasps) are particularly prone to conflicts because males generally develop from unfertilized haploid eggs, while females (workers and queens) arise from fertilized diploid eggs. This haplodiploid sex determination system leads to relatedness asymmetries within colonies (Trivers \& Hare 1976). Queens (reproductive females) are equally related to their sons and daughters $(r=0.5)$, whereas workers are generally more related to their full-sisters $(r=0.75)$ than to their brothers $(r=0.25)$. Kin selection theory (Hamilton 1964a,b) predicts that under Fisherian sex ratio selection such asymmetrical kin structures constitute a source of conflict over how to allocate resources to male and female

Correspondence: Stephanie Jemielity. Fax: + 412169241 65; Email: Stephanie.Jemielity@ie-zea.unil.ch brood (note that hereafter we apply the term 'female' exclusively to reproductive females) (Trivers \& Hare 1976). An equal investment in male and female reproductives is expected if the colony's allocation of resources is under the control of the queen, whereas workers can increase their inclusive fitness by investing more resources in females than males (Trivers \& Hare 1976). Under worker control the population-wide sex allocation ratio should equilibrate at $3: 1$ (female : male) when colony reproduction is monopolized by a unique single-mated (monandrous) queen. The conflict between queens and workers is predicted to decrease as the difference between the relative kin values of females and males to workers diminishes (Boomsma 1989). This is the case when relatedness asymmetries are reduced, for example, by the presence of several related queens per colony (polygyny), or when queens mate with several males (polyandry) (review in Chapuisat \& Keller 1999).

Sex-ratio manipulation by workers has been demonstrated in a number of social Hymenoptera (e.g. Mueller 
1991; Sundström 1994; Evans 1995; Sundström et al. 1996; Hammond et al. 2002; reviews by Nonacs 1986; Queller \& Strassmann 1998; Chapuisat \& Keller 1999). In several species workers from colonies with higher-than-average relatedness asymmetries invest mainly in females, whereas workers from colonies with low relatedness asymmetries favour the production of males (e.g. Mueller 1991; Sundström 1994; Evans 1995; Sundström et al. 1996). Furthermore, a reduction in the proportion of males between the egg and adult stages seems to be common in ants (Aron et al. 1994, 1995; Keller et al. 1996; Sundström et al. 1996), suggesting that one of the mechanisms by which workers bias sex ratio is male elimination.

In some species, however, workers do not bias sex allocation to their own advantage, even though a queenworker conflict seems to exist (e.g. Fjerdingstad et al. 1902; Nakata 1998; Helms 1999; Brown \& Keller 2000). Such results have been tentatively explained by the workers' inability to tell female and male brood apart (Nakata 1998; Fjerdingstad et al. 2002) or to assess effectively the relatedness asymmetries within colonies (Fjerdingstad et al. 2002). Alternatively, queens may control sex allocation by limiting the number of female eggs (Pamilo 1982; Pamilo \& Rosengren 1983; Passera et al. 2001; Reuter \& Keller 2001; Fjerdingstad et al. 2002), or by controlling caste determination (Pamilo 1982; Helms 1999).

The first of these explanations (that workers fail to bias sex ratio because they lack brood sex discrimination cues) builds on the concept of sexual deception (Nonacs \& Carlin 1990; Nonacs 1993). The sexual deception hypothesis postulates that queens conceal the gender of their brood to keep control over sex allocation: uncertainty about gender should prevent workers from culling males because mistakenly destroying highly related females could be very costly. Similarly, sexual deception might enable the queen to monopolize male parentage. In some ant species workers are not sterile and try to increase their fitness by laying male eggs. However, if workers can recognize males only at an advanced stage of development, the workers' fitness return from raising their brothers to adulthood might be higher than that of replacing them with sons (Nonacs \& Carlin 1990). As for the males, they should be selected to contribute to sexual deception by mimicking females to be spared by the workers (Keller \& Nonacs 1993).

Sexual deception should hold up as long as replacing queen-produced males by females or worker-produced males yields an additional inclusive fitness payoff for workers (Nonacs 1993; Chapuisat et al. 1997). However, once males have passed a certain stage of development, replacing them is no longer beneficial for workers. To date, although there is some evidence consistent with sexual deception (Nonacs \& Carlin 1990; Nakata 1998), it is still too early to reach a decision on whether sexual deception constitutes an aspect of queen control or not.
In this study we attempt to determine whether workers of the black garden ant, Lasius niger, are able to discriminate between male and female brood. We furthermore examine with the aid of two models (Nonacs \& Carlin 1990; Chapuisat et al. 1997) whether sexual deception might play a role in this species. Lasius niger is of particular interest for such investigations because this species encompasses all conditions rendering sexual deception likely. First, workers are capable of producing viable haploid eggs (van der Have et al. 1988), but the queen seems to largely dominate male parentage (Fjerdingstad et al. 2002). Second, worker policing (workers' preventing each other from laying eggs) is not predicted on relatedness grounds (Nonacs 1993) because colonies contain a single queen which usually mates only once or twice. Finally, the overall investment in females in our study population is close to $1: 1$, the queen optimum (Fjerdingstad et al. 2002; for sex-ratio studies in other L. niger populations see also Boomsma et al. 1982; Pearson 1987; van der Have et al. 1988).

\section{Materials and methods}

\section{The organism}

Lasius niger ants are widespread and abundant in the holarctic region (Wilson 1955). They generally form singlequeen (monogynous) colonies, and most of the queens mate only once or twice (van der Have et al. 1988; Fjerdingstad et al. 2002). According to Forel (1920), queens lay the bulk of their eggs in early autumn. After hatching and overwintering, larvae resume their development into workers and female or male reproductives by early summer of the following year. Mating flights take place between July and August in Switzerland.

\section{Sampling}

In March 2000 we located 142 L. niger colonies in a meadow on the campus of the University of Lausanne and covered them with concrete slabs $(40 \times 40 \mathrm{~cm})$. The particular conditions of temperature and humidity under the slabs induce workers to bring the brood up to the slabs, thus making it possible to sample larvae and prepupae (larvae which have already spun their cocoon) repeatedly without damaging the nests (e.g. Boomsma et al. 1982; Pearson 1987).

Larvae found under the slabs of these 142 colonies were sampled for the first time between 21 March and 10 April. Two or three further samplings were made at intervals of about 20 days, ending by 22 May when all larvae had become prepupae or pupae. Each sample consisted (if possible) of about 60 larvae and/or prepupae, as well as 24 adult workers, collected in the uppermost nest chambers (i.e. those accessible when the slabs were lifted) with the 
aid of a field aspirator. Larvae from different nest chambers were sampled into separate tubes. Samples were stored at $-20^{\circ} \mathrm{C}$.

\section{Brood sexing}

The gender of 849 larvae and prepupae from 15 selected colonies (range: 10-28 per sampling date and colony) was determined on the basis of their genotype at the highly polymorphic microsatellite locus L10-53 (Fjerdingstad et al. 2002). We chose colonies that produced both many males and many reproductive females and/or colonies in which tiny larvae (which turned out to be males) were found in early samples. L10-53 heterozygotes could be reliably considered as diploid females or workers, and the homozygotes as haploid males because in all colonies 24 previously analysed adult workers and/or queen prepupae were all found to be heterozygous (queen prepupae can be easily distinguished from male and worker prepupae by their size, see Results). Moreover, the estimated error in sexing, based on allele frequencies and binomial probabilities, was below $1.5 \%$ in all colonies.

First the length and fresh weight of all individuals were determined. Then, DNA was extracted and polymerase chain reaction (PCR) and gel electrophoresis were performed as described in Fjerdingstad et al. (2002) with the following modifications: (i) after DNA extraction the redissolved DNA was diluted 10-1000 times according to the larval weight and (ii) the $\mathrm{MgCl}_{2}$ concentration in the PCR reactions was $2 \mathrm{~mm}$.

\section{The timing of fratricide and sexual deception}

To date, two models have been developed to determine up to what stage in male development workers should replace brothers by sisters (Chapuisat et al. 1997) or by their own sons and nephews (Nonacs \& Carlin 1990). Brothers should be replaced as long as the inclusive fitness payoff per unit of resources still to be invested in sisters or worker-produced males is greater than that for brothers (Chapuisat et al. 1997). The developmental threshold until which replacing brothers would be advantageous for workers also delimits the minimal time frame during which sexual deception must hold up to be efficient (Nonacs 1993).

According to the model of Chapuisat et al. (1997), workers would benefit from replacing queen-produced males by female reproductives as long as

$x<1-\left[F C b_{m} V_{m} /(1-F) b_{f} V_{f}\right]$

or, if part of the resources invested in males can be recycled into females by cannibalism (see Chapuisat et al. 1997), as long as
$x<\left[(1-F) b_{f} V_{f}-F C b_{m} V_{m}\right] /\left[(1-F) b_{f} V_{f}-E F b_{m} V_{m}\right]$

In these two equations $x$ represents the fraction of the total resources needed to rear a male to adulthood that has already been invested in a developing male at the time of its potential elimination. $b_{m}$ and $b_{f}$ represent the regression relatedness of males and females to workers and $V_{m}$ and $V_{f}$ represent their respective reproductive values. The products $b_{m} V_{m}$ and $b_{f} V_{f}$ are also called 'life-for-life relatedness' of males and females to workers (see Bourke \& Franks 1995; pp. 78-79). $C$ is the female-to-male energetic cost ratio, which corresponds to the dry weight ratio corrected for sex-specific metabolic rates by a 0.7 power conversion (Boomsma 1989; Boomsma et al. 1995). F represents the population-wide proportion of females or 'lumped mean proportion of females' (population-wide number of females/ population-wide number of males plus females) and $E$ is the proportion of resources invested in males that can be recycled into females when males are eliminated. To calculate $x$ for L. niger we used data from Fjerdingstad et al. (2002) as empirical estimates of the aforementioned variables.

The Nonacs and Carlin model (Nonacs \& Carlin 1990), which has here been extended to consider various queen mating frequencies, predicts that $L$. niger workers should replace brothers by their own sons or nephews as long as

$b_{q} V_{q} / Y-y<b_{w} V_{w} / Y$

where $Y$ is the total amount of resources needed to raise a male to adulthood and $y$ represents the resources invested in a queen-produced male at the moment of its potential elimination. $b_{w} V_{w}$ and $b_{q} V_{q}$ represent the life-for-life relatedness of workers to worker-produced and queenproduced males, respectively.

Solving the above equation for $y$ gives

$y<\left[1-b_{q} V_{q} / b_{w} V_{w}\right] Y$

To determine whether the males found during our first sampling were already beyond the developmental thresholds predicted by these two models, we determined the fraction of resources invested in these males compared to the total investment needed to produce adult males. The total amount of resources needed to produce adult males was estimated on the basis of the dry weight of 43 male prepupae from six colonies (range 2-13 per colony). We used prepupae instead of adult males for this estimation because in L. niger and many other ants male dry weight decreases after pupation (Boomsma \& Isaaks 1985; Chapuisat et al. 1997). The amount of resources invested in males collected during the first sampling was determined by measuring the dry weight of 80 male larvae from four colonies (range 15-29 per colony). All larvae and prepupae were weighed after $48 \mathrm{~h}$ of drying at $50^{\circ} \mathrm{C}$. 


\section{Results}

Throughout the sampling period we were able to determine the gender and putative caste of all larvae examined. Male brood could be distinguished from worker and female brood by analysing the L10-53 microsatellite locus, while worker and female larvae or prepupae could be distinguished because of their different sizes. In the fourth sample the size dimorphism between worker and female brood was considerable, and therefore an unambiguous indicator of caste (Table 1; discrimination analysis; Wilks' $\left.\Lambda=0.016 ; F_{1,26}=1563 ; P<0.0001\right)$. In the first three samples almost all diploid larvae found were of similar size, but three lines of evidence indicate that they were queen larvae. First of all, they were already as big as worker larvae and prepupae collected during the fourth sampling (Table 1 ; paired $t$-test; $t_{9}=-1.05 ; P=0.32$ ). Second, no larvae developed into worker prepupae for more than a month after the first sample was collected (Table 1). Finally, out of 73 diploid larvae collected from five field colonies on 4 April 2002, all surviving larvae (41 out of 73) developed into queens in the laboratory.

There were two categories of colonies. Fourteen of the 15 colonies examined produced both male and female reproductives as well as workers (in colony L88 we did not find worker larvae but they were presumably also produced), whereas in one nest (L51) only male and worker brood were found (Table 1). Subsequent visual inspection of colony L51 confirmed that it did not produce reproductive females throughout the summer.

The mean size ( \pm SD) of male brood was $1.82 \pm 0.08 \mathrm{~mm}$ in the first sample and increased by $211 \%$ to $3.84 \pm 0.63 \mathrm{~mm}$ in the fourth sample (Table 1). The mean size of worker brood was $1.96 \pm 0.25 \mathrm{~mm}$ in the first sample and increased by $155 \%$ to $3.04 \pm 0.31 \mathrm{~mm}$ in the fourth sample. Female brood had a mean size of $2.96 \pm 0.15 \mathrm{~mm}$ in the first sample, and increased its size by $256 \%$ to $7.58 \pm 0.15 \mathrm{~mm}$ in the fourth sample. In all nests even the smallest female larvae were invariably bigger than all male larvae. This difference in size was already significant at the time of our first sampling (Table 1; Mann-Whitney $U$-test; $U=0.0 ; P=0.004$ ). A comparison of the fresh weight (data not shown) showed that the increase in weight between the first and the fourth sample was significantly higher for female (18fold) than for male larvae (nine-fold; Mann-Whitney $U$ test; $U=0.0 ; P=0.01$ ).

\section{Brood sex discrimination}

Our data indicate that workers were able to distinguish between male and female reproductive larvae during the whole sampling period. In the 14 male and queenproducing colonies, all first samples (collected between the end of March and the beginning of April) were highly biased with regard to the sex ratio of the larvae found. In 11 colonies we found only queen larvae, although males must have been present in the nests because males were found in the fourth sampling (Table 1) and because they develop from hibernated larvae (Forel 1920; V. Kipyatkov, personal communication). In contrast, in the three other colonies only males were found in the first samples, whereas both male and female reproductives were found in subsequent samples. This first-sample bias indicates that workers keep male and female brood in separate brood chambers.

Like the first sample, intermediate samples generally consisted of queen larvae only (Table 1), confirming that workers treat male and queen brood differently. Male larvae were found at the same time as queen larvae in only three cases, and even then the two genders were neatly grouped in separate brood chambers.

\section{Sexual deception}

To determine until what stage in male development workers could enhance their inclusive fitness by replacing males with female reproductives, we empirically estimated the variables of the Chapuisat et al. model (Chapuisat et al. 1997). In monogynous colonies with a single-mated queen the life-for-life relatedness of workers to brothers $b_{m} V_{m}$ and to sisters $b_{f} V_{f}$ equals 0.25 and 0.75 , respectively, provided that queens are outbred and monopolize the production of males (these two conditions appear to be approximately fulfilled in the population examined, Fjerdingstad et al. 2002). In a colony with a double-mated queen $b_{m} V_{m}$ remains 0.25 , whereas $b_{f} V_{f}$ becomes 0.5 . The average female-to-male energetic cost ratio for 1997 and 1998 was 7.66 in our population (Fjerdingstad et al. 2002) and the population-wide proportions of female reproductives were $14.2 \%$ and $13.2 \%$ in 1997 and 1998, respectively (calculated from Fjerdingstad et al. 2002). Introducing all these estimates into the equations of Chapuisat et al. (1997) (see Material and methods section) reveals that in monandrous colonies workers would benefit from replacing males by female reproductives up until $58 \%$ of the total male development (Table 2). In colonies with a double-mated queen, workers could increase their inclusive fitness by replacing males in which less than $37 \%$ of the total resources needed have been invested (Table 2). Whether or not the resources invested in the eliminated males can be recycled by cannibalism (we assumed that the amount of resources that can be recycled is either 0 or $45 \%$, see Chapuisat et al. 1997) appears to have hardly any influence on the predicted timing of fratricide (Table 2).

Our data show that first-sample male larvae were at a stage of development at which workers would have benefited from killing them and raising female reproductives 
Table 1 Caste and length in $\mathrm{mm}($ mean \pm SD) of the larvae and prepupae sampled

\begin{tabular}{|c|c|c|c|c|}
\hline Colony & $\begin{array}{l}\text { First sample (pooled) } \\
21.3 .2000-8.4 .2000\end{array}$ & $\begin{array}{l}\text { Second sample } \\
14.4 .2000-19.4 .2000\end{array}$ & $\begin{array}{l}\text { Third sample } \\
\text { 25.4.2000-11.5.2000 }\end{array}$ & $\begin{array}{l}\text { Fourth sample } \\
19.5 .2000 \text { or } 22.5 .2000\end{array}$ \\
\hline L15 & QL: $2.74 \pm 0.25(28)$ & QL: $2.68 \pm 0.33(16)$ & OL: $>5.18 \pm 0.96(16)$ & $\begin{array}{l}\text { ML: } \mathbf{3 . 0 4} \pm \mathbf{0 . 3 5} \text { (18) } \\
\text { WL: } 3.21(1) \\
\text { OP: } 7.71 \pm 0.17 \text { (3) }\end{array}$ \\
\hline L30 & & & & $\begin{array}{l}\text { MP: } 4.43 \pm 0.19(7) \\
W P: 2.93(1)\end{array}$ \\
\hline & QL: $2.93 \pm 0.28(30)$ & QL: > $3.60 \pm 0.35$ (20) & QL: $>4.14 \pm 1.00(10)$ & QP: $7.31 \pm 0.12(4)$ \\
\hline L35 & $0 \mathrm{O} \cdot 284+036(16)$ & 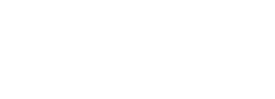 & 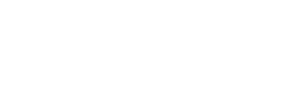 & $\begin{array}{l}\text { MP: } \mathbf{4 . 6 2} \pm \mathbf{0 . 1 7}(\mathbf{5}) \\
W P: 3.19 \pm 0.19(7)\end{array}$ \\
\hline L43 & _ _ _ _ _ _ . . & $-\ldots-\ldots$ & $\ldots \ldots \ldots$ & $\begin{array}{l}\text { ML: } 3.51 \pm 0.09(4) \\
W L: 2.88 \pm 0.25(6)\end{array}$ \\
\hline & QL: $3.14 \pm 0.31(42)$ & & QL: > $3.99 \pm 0.74$ (12) & QP: $7.32 \pm 0.38$ (3) \\
\hline L48 & QL: $3.08 \pm 0.22(24)$ & & $\begin{array}{l}\text { ML: } 1.90 \pm 0.21(\mathbf{1 2}) \\
\text { QL: > } 3.58 \pm 0.62(8)\end{array}$ & $\begin{array}{l}\text { ML: } 3.48 \pm \mathbf{0 . 6 0}(\mathbf{8}) \\
W L: 2.60 \pm 0.03(3) \\
\text { QP: } 7.79 \pm 0.18(11)\end{array}$ \\
\hline L55 & QL: $3.10 \pm 0.19(16)$ & & QL: > $3.77 \pm 0.47(16)$ & $\begin{array}{l}\text { MP: } 4.46 \pm 0.13(7) \\
W P: 3.54 \pm 0.08(6) \\
Q P: 7.58 \pm 0.24(3)\end{array}$ \\
\hline L56 & QL: $3.06 \pm 0.29$ (17) & & & $\begin{array}{l}\text { MP: } \mathbf{4 . 5 2} \pm \mathbf{0 . 1 4}(\mathbf{3}) \\
W P: 3.61 \pm 0.23(9) \\
\text { QP: } 7.54 \pm 0.14(4)\end{array}$ \\
\hline L57 & QL: $2.89 \pm 0.22(21)$ & QL: $3.05 \pm 0.40(16)$ & QL: > $4.59 \pm 1.19(16)$ & $\begin{array}{l}\text { ML: } \mathbf{3 . 4 6} \pm \mathbf{0 . 1 3}(\mathbf{6}) \\
W L: 2.98 \pm 0.13(6) \\
\text { QP: } 7.46 \pm 0.34(2)\end{array}$ \\
\hline L88 & QL: $2.86 \pm 0.17(16)$ & QL: $3.23 \pm 0.27(16)$ & QL: $>4.77 \pm 0.85(15)$ & $\begin{array}{l}\text { ML: } 2.90 \pm 0.36(15) \\
\text { QP: } 7.74 \pm 0.05(3)\end{array}$ \\
\hline L92 & QL: $2.76 \pm 0.27$ (15) & & & $\begin{array}{l}\text { MP: } \mathbf{4 . 4 3} \pm \mathbf{0 . 1 4}(\mathbf{5}) \\
W P: 3.22 \pm 0.15(7) \\
\text { QP: } 7.62 \pm 0.12(4)\end{array}$ \\
\hline L101 & QL: $3.12 \pm 0.22(16)$ & QL: $3.31 \pm 0.26(16)$ & & $\begin{array}{l}\text { ML: } \mathbf{3 . 6 1} \pm \mathbf{0 . 5 2} \mathbf{( 1 1 )} \\
W L: 2.77 \pm 0.37(2) \\
\text { QP: } 7.73 \pm 0.09(3)\end{array}$ \\
\hline L12 & ML: $1.90 \pm 0.14(18)$ & & $\begin{array}{l}\text { ML: } \mathbf{2 . 1 2} \pm \mathbf{0 . 1 7}(\mathbf{1 6}) \\
W L: 2.19(1) \\
\text { QL: }>3.45 \pm 0.49(11)\end{array}$ & $\begin{array}{l}W P: 2.95(1) \\
\text { QP: } 7.55 \pm 0.16(9)\end{array}$ \\
\hline L130 & ML: $1.85 \pm 0.21(22)$ & $\begin{array}{l}\text { ML: } 1.66 \pm 0.13 \text { (17) } \\
\text { QL: } 2.99 \pm 0.32(9)\end{array}$ & & $\begin{array}{l}\text { ML: } 3.33 \pm 0.42(8) \\
W L: 2.68 \pm 0.11(4) \\
\text { QP: } 7.57 \pm 0.22(13)\end{array}$ \\
\hline L136 & ML: $1.71 \pm 0.11$ (21) & & & $\begin{array}{l}\text { ML: } 3.39 \pm 0.34(6) \\
W L: 2.75 \pm 0.38(5) \\
Q P: 7.68 \pm 0.07(8)\end{array}$ \\
\hline L51 & $\begin{array}{l}\text { ML: } \mathbf{1 . 8 0} \pm \mathbf{0 . 1 4}(\mathbf{1 8 )} \\
W L: 1.96 \pm 0.25(2)\end{array}$ & & $\begin{array}{l}\text { ML: } 2.07 \pm 0.16(18) \\
W L: 1.92 \pm 0.34(2)\end{array}$ & $\begin{array}{l}\text { MP: } 4.62 \pm 0.11(7) \\
W P: 3.16 \pm 0.14(16)\end{array}$ \\
\hline $\begin{array}{l}\text { Mean size } \\
\pm \text { SD }\end{array}$ & $\begin{array}{l}\text { ML: } \mathbf{1 . 8 2} \pm \mathbf{0 . 0 8}(\mathbf{4}) \\
W L: 1.96 \pm 0.25(1) \\
\text { QL: } 2.96 \pm 0.15(11)\end{array}$ & & & $\begin{array}{l}\text { ML/MP: } 3.84 \pm \mathbf{0 . 6 3} \text { (14) } \\
W L / W P: 3.04 \pm 0.31(14) \\
\text { QP: } 7.58 \pm 0.15(14)\end{array}$ \\
\hline
\end{tabular}

The number of members of each caste found among the individuals analysed or the number of colonies used to calculate the mean are given in parentheses. The mean length of larvae/prepupae in the second and third sample are not given because they are not relevant. Since larval growth between 21 March and 8 April was not significant (paired $t$-tests in four colonies where samples from the beginning and the end of this period were available: all $n=10-12$; all $P>0.14$ ), all these data were pooled and referred to as 'first sample'. $>$ denotes that smaller larvae were preferentially analysed because they were more likely to be males than larger larvae. Empty spots indicate that no larvae were found in the upper parts of the nest during this sampling period. $\mathrm{QL}=$ queen-potential larvae, $\mathrm{ML}=$ male larvae, $\mathrm{WL}=\mathrm{worker}$ larvae, $\mathrm{QP}=$ queen prepupae, $\mathrm{MP}=$ male prepupae, $\mathrm{WP}$ = worker prepupae. 
Table 2 Developmental thresholds (\% of total male development) until which workers of monogynous, monandrous colonies, or monogynous colonies with a double-mated queen benefit from replacing queen-produced males by female reproductives (1) or by workerproduced males (2)

\begin{tabular}{|c|c|c|c|c|c|c|}
\hline & \multicolumn{4}{|c|}{$\begin{array}{l}\text { (1) Male-by-female replacement } \\
\text { thresholds }(\%)\end{array}$} & \multirow{2}{*}{\multicolumn{2}{|c|}{$\begin{array}{l}\text { (2) Male-by-male replacement } \\
\text { thresholds }(\%) \\
\text { Without recycling }\end{array}$}} \\
\hline & \multicolumn{2}{|c|}{ Without recycling } & \multicolumn{2}{|c|}{$45 \%$ recycling } & & \\
\hline & $\mathrm{F}_{97}$ & $\mathrm{~F}_{98}$ & $\mathrm{~F}_{97}$ & $\mathrm{~F}_{98}$ & $\begin{array}{l}\text { Laying } \\
\text { workers }\end{array}$ & $\begin{array}{l}\text { Non-laying } \\
\text { workers }\end{array}$ \\
\hline Single-mated queen & 58 & 61 & 59 & 63 & 50 & 33 \\
\hline Double-mated queen & 37 & 42 & 38 & 43 & 50 & 0 \\
\hline
\end{tabular}

For (1) thresholds are given for both the 1997 and the 1998 lumped mean proportion of females $\left(\mathrm{F}_{97}\right.$ and $\left.\mathrm{F}_{98}\right)$ without recycling, or when $45 \%$ of the resources invested in the eliminated male can be recycled into females by cannibalism. For (2) thresholds are given for both laying and non-laying workers.

instead. The mean dry weights $( \pm S D)$ of the male larvae found in the first samples of four of our colonies were $0.16 \pm 0.03 \mathrm{mg}, 0.17 \pm 0.03 \mathrm{mg}, 0.11 \pm 0.03 \mathrm{mg}$ and $0.12 \pm$ $0.02 \mathrm{mg}$, whereas the mean dry weight $( \pm \mathrm{SD})$ of the male prepupae (which we take as the equivalent of the total investment) was $1.51 \pm 0.12 \mathrm{mg}$. Expressed as percentage of total male development these first-sample dry weights correspond to $11 \%, 11 \%, 7 \%$ and $8 \%$, and all these values are significantly lower than the developmental thresholds for male-by-female replacements in colonies with a singlemated $(58 \%)$ or a double-mated queen $(37 \%)$ ( $t$-tests; four colonies; all $P<0.0001$ ).

To determine the thresholds beyond which replacing brothers by sons or nephews no longer pays for workers, we estimated the relatedness values for the model of Nonacs \& Carlin (1990). Since their life-for-life relatedness to brothers $\left(b_{q} V_{q}\right)$ and worker-produced males $\left(b_{w} V_{w}\right)$ equals 0.25 and 0.375 , respectively, nonlaying workers of monogynous, monandrous colonies should cull brothers and replace them by nephews before $33 \%$ of the total investment has been completed (Table 2). Laying workers in the same nests would benefit from eliminating brothers $\left(b_{q} V_{q}=0.25\right)$ to raise their own sons $\left(b_{w} V_{w}=0.5\right)$ until 50\% of the total male development (Table 2).

In colonies with a double-mated queen, nonlaying workers are equally related to their sisters' and their mother's sons $\left(b_{q} V_{q}=b_{w} V_{w}=0.25\right)$ and therefore should not care about who lays the haploid eggs. Laying workers, however, are still twice as related to their own sons as to the queen's sons $\left(b_{q} V_{q}=0.25, b_{w w} V_{w}=0.5\right)$ and therefore culling brothers would be beneficial for them if less than $50 \%$ of the total resources needed to raise a male have already been invested (Table 2).

An analysis of the developmental stages of males collected during the first sampling shows that in all colonies males were significantly below the elimination thresholds for both colonies with single- and multiple-mated queens ( $t$-tests; four colonies; all $P<0.0001)$. Hence, workers could have increased their inclusive fitness by replacing these males with their sons.

\section{Discussion}

\section{Brood sex discrimination and differential brood raising}

Our study demonstrates that workers are able to discriminate between male and female brood very early during larval development. In all colonies examined, the first samples collected after overwintering, when male larvae were only at $11 \%$ of their final dry weight, were highly biased towards either queen larvae or male larvae. However, because all but one of these colonies produced both male and female reproductives and because reproductive larvae develop from hibernated larvae (Forel 1920; V. Kipyatkov, personal communication) both male and female reproductive larvae must have been present during all samplings, even if we did not find them. Among 14 male- and female-producing nests, in three colonies first samples consisted of only male larvae, whereas in the 11 other nests first samples consisted of only female larvae. This bias must be the result of worker activity because they transport larvae under the slabs and remove them again at least once a day. Further evidence that workers play an active part in sorting brood according to sex comes from analyses of egg samples (S. Jemielity, unpublished data, see below). These samples contained both male and female eggs, indicating that the separation of male and female brood happens only at the larval stage and that it cannot be due to the queen laying male and female eggs in different nest chambers.

The clear spatial separation of male and female larvae also suggests that they are raised differentially during 
some stages of their development. In most colonies (10 out of 15 colonies analysed, but 124 out of 142 colonies sampled) only queen larvae were found under the slabs until mid-May. This suggests that queen larvae were kept at relatively high temperatures, whereas male and worker larvae were located in deeper, colder parts of the nests. A similar spatial segregation between queen larvae and the remaining brood has been recorded by Boomsma \& Isaaks (1985) for two Dutch Lasius niger populations. Differential treatment of male and queen larvae might arise from the need to synchronize male and female development: given the extreme size dimorphism in L. niger, queen larvae have to grow a lot faster than males to meet the shared deadline of development. Alternatively, male, queen and worker brood may simply require different microclimatic conditions for optimum development. Temperature, for example, has been shown to affect strongly the caste determination of the ant Myrmica rubra: as little as a $2{ }^{\circ} \mathrm{C}$ increase in temperature at the larval stage was associated with an eight-fold increase in worker production and a decrease in queen-production (Brian 1973).

One possible cue that would allow workers to discriminate between male and female larvae is their difference in size. All first-sample male larvae were much smaller than first-sample queen larvae. This result is in accord with Boomsma \& Isaaks (1985), who claim (but do not provide data) that $L$. niger male and queen brood can be distinguished by their morphology relatively early (but later than described in the present study). It is noteworthy that this size-dimorphism between male and female larvae can itself be regarded to some extent as evidence for brood sex discrimination by workers.

\section{Sexual deception and sex ratio}

Our results show that sexual deception cannot account for the apparent queen control over colony sex ratio that has been reported by Fjerdingstad et al. (2002) in the Lausanne population. Workers were already able to distinguish between male and queen larvae during the first sampling, a time at which it would still have been very advantageous for workers to kill male larvae and replace them by females. In fact, workers were able to recognize male larvae when they were at a developmental stage that was more than three times less advanced in terms of dry weight than the various thresholds for male-by-female replacements.

Our conclusion, that workers did not eliminate males although it would have been advantageous for workers to do so, is sufficiently robust to allow for some imprecisions in our estimates. A first potential source of imprecision comes from our using dry weight as a measure of investment. This may lead to biases if the intrinsic metabolic rate varies with the size of larvae, which indeed seems to be the case in L. niger. Boomsma \& Isaaks (1985) found that young larvae have an intrinsic metabolic rate that is twice as low as that of larvae close to pupation. It is therefore likely that we overestimated the relative investment in our firstsample males and that workers would have benefited from eliminating males at an even greater size than that estimated here. Our conclusion is thus conservative. Another potential error would arise if the population-wide proportion of females and the female-to-male energetic cost ratio varied from year to year. However, the population-wide proportion of females in the Lausanne population seems to be very stable from year to year (Fjerdingstad et al. 2002; see also Results). Moreover, for colonies with a monandrous queen our results would remain qualitatively the same even if the population-wide proportion of females were almost twice as high (25\%) as recorded (13-14\%). Similarly, for colonies with a double-mated queen our results would remain the same even if the populationwide proportion of females were almost 30\% higher (18\%) than that recorded (13-14\%). Finally, the female-to-male energetic cost ratio also appears to remain stable over the years. In the population investigated the energetic cost ratios from 1997 and 1998 did not differ significantly (E. J. Fjerdingstad, personal communication) and their average was equal to the energetic cost ratio recorded by Boomsma \& Isaaks (1985) for a Dutch population of L. niger (Fjerdingstad et al. 2002).

Our finding that workers are able to recognize males at a very early stage of development raises the question of why they did not replace them with females. One reason might be that the quantity of diploid larvae with the potential to develop into queens is limited, which would prevent workers from recycling the energy provided by male elimination into the production of new females. Limitation of diploid brood has been shown theoretically to be an effective means by which queens can prevent workers from biasing colony sex ratio toward more females (Reuter \& Keller 2001). Interestingly, studies of the primary sex ratio in L. niger show that the queen-determined primary sex ratio at the end of June is highly bimodal (S. Jemielity, unpublished data). This suggests that workers from colonies with a highly male-biased primary sex ratio might have no better option than raising the males to adulthood. Moreover, time constraints associated with the particular life cycle of $L$. niger could enhance the effect of diploid brood limitation by imposing a deadline after which males could no longer be replaced with females. Finally, if the queen and worker developmental pathways diverge relatively early during larval development, this may act as an additional constraint that prevents workers from profitably replacing males by females (Pamilo 1982; Helms 1999).

The finding that male and female brood are kept in distinct locations within the nest raises the question of whether differences in the optimum growth conditions of 
male and female larvae might prevent sexual deception. The need to raise brood differentially is likely to be associated with substantial size dimorphism between males and females, which is very common in ants and other aculeate species (Stubblefield \& Seger 1994). Thus, if male and female ant brood differ in their optimum growth conditions, as might be the case in L. niger, brood sex discrimination by workers could have an important impact on colony productivity and might therefore be favoured by natural selection. In such a scenario sexual deception would be considerably limited. Moreover, it has been known for a long time that most ant species sort brood into piles of different sizes (Carlin 1988). If this spatial segregation between larvae of different size turned out to be a spatial segregation between larvae of different genders (as is the case in L. niger), brood sex discrimination by workers might, in fact, be very common in ants with strongly sizedimorphic reproductives.

\section{Sexual deception and worker reproduction}

Our study also shows that the queen dominance over male parentage in the Lausanne population (Fjerdingstad et al. 2002) cannot be explained by sexual deception. Applying the Nonacs (1993) model to our data revealed that workers were already able to discriminate male brood at a time when males were still well below the various threshold developmental stages beyond which replacing brothers by sons or nephews ceases to be beneficial for workers. As for the other model, our conclusion is robust enough to withstand errors in the estimates of the parameters. The only parameter that might constitute a source of error is the energy investment in males which might not be constant over time. However, taking the relatively lower metabolic rate of young males into account would render our results even more significant. Hence, sexual deception is manifestly not the factor that protects queen-laid males from being eliminated by workers.

There are three possible explanations for why workers did not replace queen-produced males by their own offspring even though they were able to recognize males early enough to profitably eliminate them. First, the model of Nonacs \& Carlin (1990) assumes that workers are able to distinguish queen-produced males from worker-produced males, which may not be true. Second, it is possible that constraints on the timing of male production may prevent workers from replacing queen-produced eggs by their own. For example, workers might reap no benefit from replacing queen-produced male larvae with their own eggs if these eggs are unlikely to develop fast enough to give rise to adult males by the time of mating flights. Finally, worker reproduction might be associated with an overall decrease in colony productivity. If that cost is higher than the benefits of selfishly reproducing, workers might mutually prevent each other from laying eggs (Ratnieks 1988)

In conclusion, our study shows that L. niger workers are able to discriminate between male and queen larvae very early in their development. Brood sex discrimination allows workers to raise male and female brood at different microclimatic conditions after hibernation, which may be important in species with substantial sexual size dimorphism such as L. niger. Finally, the ability of workers to identify males accurately during their larval development implies that sexual deception cannot account for the apparent queen control over sex ratio and male parentage in the population investigated.

\section{Acknowledgements}

We would like to thank Y. Chuât, D. Jemielity, P. Langer, J. Parker and C. Roger for assistance in the field or laboratory and A. Bourke, M. Chapuisat, E. J. Fjerdingstad, R. Hammond, D. Jemielity, P. Nonacs, D. Queller and an anonymous referee for helpful comments on earlier versions of this manuscript. This work was supported by several grants from the Swiss NSF.

\section{References}

Aron S, Passera L, Keller L (1994) Queen-worker conflict over sex ratio: a comparison of primary and secondary sex ratios in the argentine ant. Iridomyrmex Humilis Journal of Evolutionary Bio$\log y, 7,403-418$.

Aron S, Vargo El Passera L (1995) Primary and secondary sex ratios in monogyne colonies of the fire ant. Animal Behaviour, 49, 749-757.

Boomsma JJ (1989) Sex-investment ratios in ants: has female bias been systematically overestimated? American Naturalist, 133, 517-532.

Boomsma JJ, Isaaks JA (1985) Energy investment and respiration in queens and males of Lasius niger (Hymenoptera: Formicidae). Behavioral Ecology and Sociobiology, 18, 19-27.

Boomsma JJ, van der Lee GA, van der Have TM (1982) On the production ecology of Lasius niger (Hymenoptera: Formicidae) in successive coastal dune valleys. Journal of Animal Ecology, 51, 975-991.

Boomsma JJ, Keller L, Nielsen MG (1995) A comparative analysis of sex ratio investment parameters in ants. Functional Ecology, 9, 743-753.

Bourke AFG, Franks NR (1995) Social Evolution in Ants, 1st edn. Princeton University Press, Princeton.

Brian MV (1973) Temperature choice and its relevance to brood survival and caste determination in the ant Myrmica rubra $\mathrm{L}$. Physiological Zoölogy, 46, 245-252.

Brown WD, Keller L (2000) Colony sex ratios vary with queen number but not relatedness asymmetry in the ant Formica excecta. Proceedings of the Royal Society of London Series B-Biological Sciences, 267, 1751-1757.

Carlin NF (1988) Species, kin and other forms of recognition in the brood discrimination behavior of ants. In: Advances in Myrmecology (ed. Trager JC), pp. 267-295 Brill, New-York.

Chapuisat M, Keller L (1999) Testing kin selection with sex allocation data in eusocial Hymenoptera. Heredity, 82, 473-478. 
Chapuisat M, Sundström L, Keller L (1997) Sex-ratio regulation: the economics of fratricide in ants. Proceedings of the Royal Society of London Series B-Biological Sciences, 264, 1255-1260.

Evans JD (1995) Relatedness threshold for the production of female sexuals in colonies of a polygynous ant, Myrmica tahoensis, as revealed by microsatellite DNA analysis. Proceedings of the National Academy of Sciences of the USA, 92, 6514-6517.

Fjerdingstad EJ, Gertsch PJ, Keller L (2002) Why do some social insect queens mate with several males? Testing the sexratio manipulation hypothesis in Lasius niger. Evolution, 56, 553562.

Forel A (1920) Les Fourmis de la Suisse, 2nd edn. Imprimerie Coopérative, La Chaux-de-Fonds.

Hamilton WD (1964a) The genetical evolution of social behavior. 1. Journal of Theoretical Biology, 7, 1-16.

Hamilton WD (1964b) The genetical evolution of social behavior. 2. Journal of Theoretical Biology, 7, 17-52.

Hammond RL, Bruford MW, Bourke AFG (2002) Ant workers selfishly bias sex ratios by manipulating female development. Proceedings of the Royal Society of London Series B-Biological Sciences, 269, 173-178.

Helms KR (1999) Colony sex ratios, conflict between queens and workers, and apparent queen control in the ant Pheidole desertorum. Evolution, 53, 1470-1478.

Keller L, Nonacs P (1993) The role of queen pheromones in social insects: queen control or queen signal? Animal Behaviour, 45, 787-794.

Keller L, Reeve HK (1999) Dynamics of conflicts within insect societies. In: Levels of Selection in Evolution (ed. Keller L), pp. 153-175. Princeton University Press, Princeton.

Keller L, Aron S, Passera L (1996) Internest sex-ratio variation and male brood survival in the ant Pheidole pallidula. Behavioral Eco$\log y, 7,292-298$.

Mueller UG (1991) Haplodiploidy and the evolution of facultative sex ratios in a primitively eusocial bee. Science, 254, 442-444.

Nakata K (1998) Absence of sex-differential brood raising by workers in Diacamma sp. from Japan. Behavioral Ecology and Sociobiology, 43, 223-227.

Nonacs P (1986) Ant reproductive strategies and sex allocation theory. Quarterly Review of Biology, 61, 1-21.

Nonacs P (1993) Male parentage and sexual deception in the social Hymenoptera. In: Evolution and Diversity of Sex Ratio in Insects and Mites (eds Wrensch DL, Ebbert DL), pp. 384-401. Chapman \& Hall, New York.
Nonacs P, Carlin F (1990) When can ants discriminate the sex of brood? A new aspect of queen-worker conflict. Proceedings of the National Academy of Sciences of the USA, 87, 9670-9673.

Pamilo P (1982) Genetic evolution of sex ratios in eusocial Hymenoptera: allele frequency simulations. American Naturalist, 119, 638-656.

Pamilo P, Rosengren R (1983) Sex ratio strategies in Formica ants. Oikos, 40, 24-35.

Passera L, Aron S, Vargo EL, Keller L (2001) Queen control of sex ratio in fire ants. Science, 293, 1308-1310.

Pearson B (1987) The sex ratio of heathland populations of the ants Lasius alienus, Lasius niger and their hybrids. Insectes Sociaux, 34, 194-203.

Queller DC, Strassmann JE (1998) Kin selection and social insects. Bioscience, 48, 165-175.

Ratnieks FLW (1988) Reproductive harmony via mutual policing by workers in eusocial Hymenoptera. American Naturalist, 132, 217-236.

Reuter M, Keller L (2001) Sex ratio conflict and worker production in eusocial Hymenoptera. American Naturalist, 158, 166-177.

Stubblefield JW, Seger J (1994) Sexual dimorphism in the Hymenoptera. In: The Differences Between the Sexes (eds Short RV, Balaban E), pp. 71-103. Cambridge University Press, Cambridge.

Sundström L (1994) Sex ratio bias, relatedness asymmetry and queen mating frequency in ants. Nature, 367, 266-268.

Sundström L, Chapuisat M, Keller L (1996) Conditional manipulation of sex ratios by ant workers: a test of kin selection theory. Science, 274, 993-995.

Trivers RL, Hare H (1976) Haplodiploidy and the evolution of the social insects. Science, 191, 249-263.

van der Have TM, Boomsma JJ, Menken SBJ (1988) Sex-investment ratios and relatedness in the monogynous ant Lasius niger (L.). Evolution, 42, 160-172.

Wilson EO (1955) A monographic revision of the ant genus Lasius. Bulletin of the Museum of Comparative Zoology at Harvard College, 113, 1-201.

This work was part of the diploma (undergraduate) thesis written by S. Jemielity, under the direction of L. Keller. The Keller laboratory uses ants and other social insects as a model system to explore such problems as sex allocation, reproductive skew, caste determination and the molecular basis of ageing 